УДК 53.09

\title{
ТЕРМОВЛАЖНОЕ СТАРЕНИЕ КОМПОЗИЦИЙ НА ОСНОВЕ ПОЛИАМИДА
}

\author{
Акаева Маднат Магомедовна \\ к.т.н., доцент \\ ФГБОУ ВО «Чеченский государственный университет \\ им. А.А. Кадырова», Академия наук ЧР
}

\begin{abstract}
Аннотация: В работе получены ПКМ на основе полиамида-6, исследовано в частности сопротивление агрессивности окружающей среды (устойчивости к температурному и механическому старению). Также практическим путем выявлены наилучшие значения концентрации вводимых добавок в полимер, которые позволили бы повысить сопротивление старению без значительной утраты прочности и ударной вязкости.
\end{abstract}

Ключевые слова: Полиамид, старение, модификатор, оксид, цинк.

\section{THERMAL AGING OF POLYAMIDE-BASED COMPOSITIONS}

\section{Akaeva Madnat Magomedovna}

Abstract: In this work, PCMs based on polyamide-6 were obtained, in particular, the resistance to aggressiveness of the environment (resistance to thermal and mechanical aging) was investigated. Also, in a practical way, the best values of the concentration of additives introduced into the polymer have been revealed, which would make it possible to increase the aging resistance without a significant loss of strength and impact strength.

Key words: Polyamide, aging, modifier, oxide, zinc.

Полиамиды - высокомолекулярные соединения, содержащие в основной цепи макромолекулы повторяющиеся амидные группы -C(0)-NH--, относятся к наиболее распространенным промышленным термопластам. Полиамиды, получаемые по реакциям ступенчатой поликонденсации и инициированной полимеризацией с раскрытием циклов, могут быть линейными, 
разветвленными, сшитыми, а также иметь циклическое строение. Все это, а также наличие комплекса великолепных физико-химических и механических свойств обеспечили полиамидам широкое применение в различных отраслях промышленности.

Важную роль в процессах переработки полиамидов (литье под давлением, прессование, экструзия и др.) играют молекулярная масса (MМ) и молекулярно-массовое распределение (MМР). Переработка полиамидов облегчается при снижении молекулярной массы, нижняя граница которой определяется необходимостью сохранения заданных механических свойств готового изделия.

На хранение и эксплуатацию полиамидных изделий существенное влияние оказывает морфология их поверхности. Рентгеноструктурный анализ линейных гомополиамидов в твердом состоянии (например, ПА-6 и ПА-66) показывает, что это - частично кристаллические материалы.

Многочисленные исследования посвящены стабилизации полиамидов при воздействии на них тепла, видимого и УФ-излучения и гидролизующих агентов. Поскольку основной функцией вводимых для этих целей веществ является уменьшение возможности окисления, и, следовательно, деструкции полимера, они называются антиоксидантами. Типичными антиоксидантами, подавляющими деструкцию полиамидов, являются органические фосфиты.

\section{Подготовка исходных веществ.}

Предварительная обработка материалов, входящих в состав композиций, заключалась в их высушивании. Этот процесс проводился в вакуумном сушильном шкафу при следующих условиях:

Полиамид-6 - $100^{\circ} \mathrm{C} 4$ часа

Оксид цинка $-75-85^{\circ} \mathrm{C} 1$ час

Помимо этого, с целью предотвращения поглощения влаги, образцы композиций в промежутке между испытаниями прибывали в эксикаторе.

\section{Технология приготовления композиционных материалов.}

После высушивания в вакуумной печи, гранулированный полиамид был взвешен и распределен по 100г на 4 части. Каждую часть смешали с оксидом цинка $(\mathrm{ZnO})$ в процентных пропорциях по массе. В Таблице 1 показано \% содержание $\mathrm{ZnO}$ в каждой из частей полиамида. 
Таблица 1

\begin{tabular}{|c|c|c|}
\hline Номер части & Полиамида в пачке. & Содержание $\mathrm{ZnO}, \%$ \\
\hline 1 & $100 г$ & 0.5 \\
\hline 2 & $100 г$ & 1.0 \\
\hline 2 & $100 г$ & 2.5 \\
\hline 4 & $100 \Gamma$ & 5.0 \\
\hline
\end{tabular}

Рабочую композиции на основе полимера (ПА-6) и высокодисперсного наполнителя (белило (оксид цинка, $\mathrm{ZnO}$ )) готовили экструзией последующей грануляцией на ленточном однозаходном экструдере.

Процесс экструдирования проводили при скорости вращения шнека (стандартный диаметр шнека 25 мм.) около 50 об/мин. Температурный режим червячного канала (цилиндра) и формующей головки (сопла) определяется особенностями экструдируемого полимера или его композиции. В нашем случае процесс экструдирования проводили при температуре материального цилиндра $237^{\circ} \mathrm{C}$, для 2-й и 3-й зон по $246^{\circ} \mathrm{C}$ и температуре формующей головки $230^{\circ} \mathrm{C}$.

Заготовки из ПКМ формы «двойной лопатки» были помещены на 3, 6 и 9 суток в печь термовлажностного старения, при влажности $60 \%$ и температуре $50{ }^{\circ} \mathrm{C}$. Эта печь может обеспечивать стабильную температуру до $150^{\circ} \mathrm{C}$ и влажность воздуха до $85 \%$. Полиамид-6 не является гидрофобным полимеров, однако, как и любой другой полимер способен впитывать некоторое количество воды из воздуха при его длительном нахождении в области повышенной влажности воздуха, а высокая температура способствует этому.

В проведении опытов нами была использована печь модели GT-7017, максимальной мощностью 4,5кВт от компании GOTECH Testing machines inc.

Проверка прочности на растяжение происходит на специальном оборудовании, при температуре $23+/-2^{\circ} \mathrm{C}$ в соответствии с ГОСТ 11262-80.

Заготовку нагружают возрастающей нагрузкой. Скорость роста нагрузки составляет 25 мм/мин. Компьютер, в момент разрушения фиксирует наибольшее усилие и определяет прочность при растяжении следующей формулой:

$$
\sigma_{\mathrm{P}}=\mathrm{F}_{\mathrm{P}} / \mathrm{S}_{0}
$$


где $\mathrm{F}_{\mathrm{P}}$ - нагрузка, при которой произошло разрушение образца, $\mathrm{S}_{0}-$ начальное поперечное сечение образца.

Полученные результаты были занесены на график.

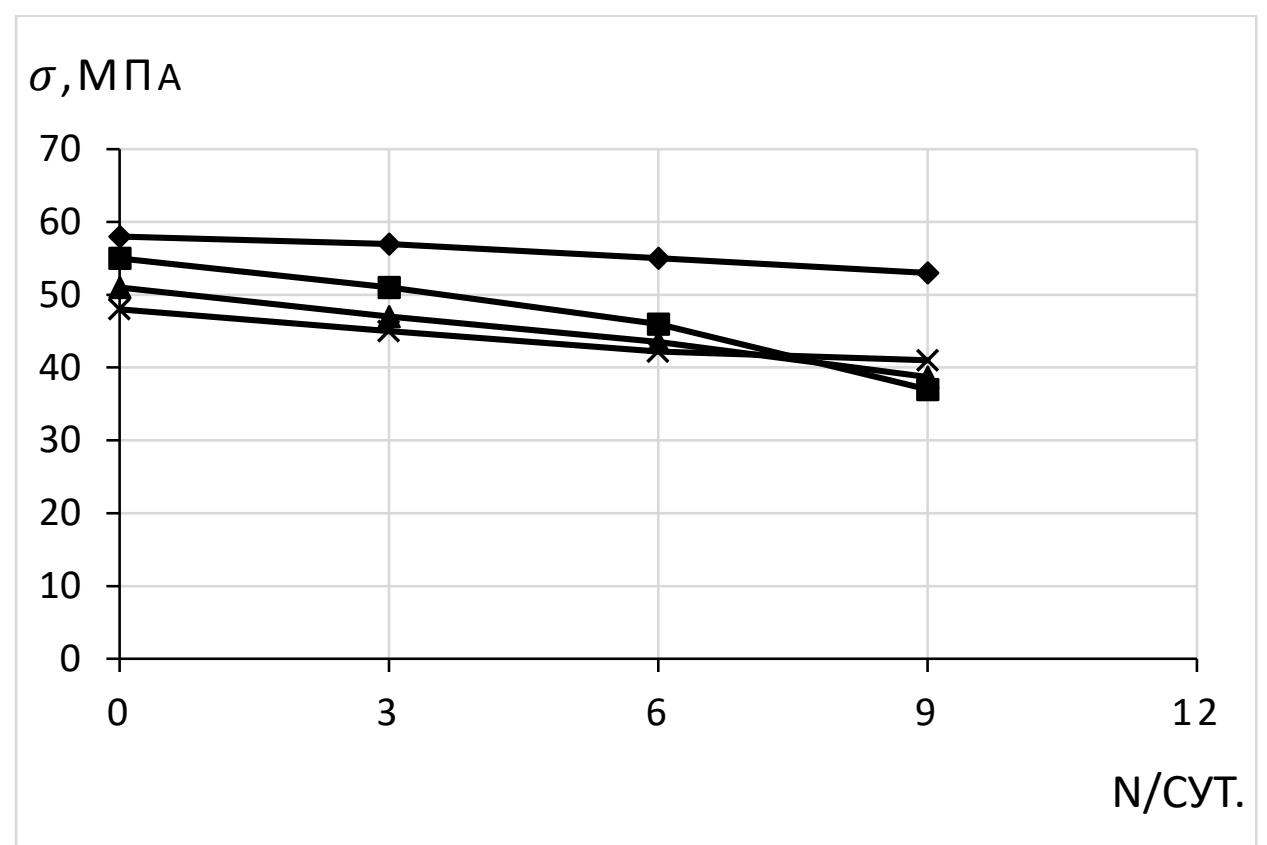

Рис. 1. График зависимости предельной прочности ПКМ с различной концентрацией оксида цинка от времени пребывания заготовок в печи в сутках

- $1(0,5 \%), \mathbf{\square}-2(1,5 \%), \mathbf{\Delta}-3(2,5 \%) \times-4(5 \%)$.

Нужно сказать, что от добавления оксида цинка, базовая прочность материала тоже снижается. Как показывает график, базовая прочность $\sigma$ ПКМ с $0,5 \%$ содержанием добавки отличается от 2,5\%-го на 7 МПа. Однако содержание этого вещества ослабляет падение прочности со временем, что хорошо показывает 4 функция для 2,5\% добавки.

Напряжение $(\sigma)$ - это единица измерения показывающая отношение нагрузки разрушения $\mathrm{P}$, к поперечной площади сечения заготовки $\mathrm{F}$.

Исходя из опытов, можно сделать вывод, что внедрение оксида цинка ( $\mathrm{ZnO})$ в полимер полиамид-6, повышает стойкость к тремовлажностному старению. При дальнейшем использовании такого ПКМ, и внедрения его в промышленные производства стоит обратить внимание, на то, что базовая прочность такого ПКМ, немного ниже чем у исходного ПА-6. 
Работа выполнена в лаборатории биосовместимых полимеров и нанокомпозитных материалов Чеченского государственного университета имени Кадырова А.А.

\section{Список литературы}

1. Акаева, М.М. Влияние минеральных наполнителей на полипропилен и полиамид / M.M. Акаева // Известия Чеченского государственного университета. 2020. № 4 (20) - С. 33-37.

2. Воробьева Г.Я. Химическая стойкость полимерных материалов. М.: Химия, 1981. -293 с.

(C) М.М. Акаева, 2021 